\title{
Mechanism Design of Multi-Attribute Reverse Auction on Margin Bid
}

\author{
Liu Biao ${ }^{a}$, Ma Benjiang ${ }^{b}$, Muhammad Farhan Bashir ${ }^{c}$ \\ School of Business, Central South University, Changsha, 410083, China \\ aliubiaocsu@163.com, b1183186495@qq.com, 'farhan.paks89@gmail.com
}

Keywords: multi-attribute auction, single-attribute auction, margin, procurement

\begin{abstract}
Designing a multi-attribute auction has many advantages in respect to attributes besides price. Nevertheless, the complexity of this method makes it hard to carry out the optimal mechanism. This paper combines the first-sealed auction mechanism with multi-attribute auction, and gives a method of transforming multi-attribute auction into single-attribute auction on margin bid. The analysis indicates that this method can just not only reduce the transaction risk caused by suppliers who will abandon the bid, but also makes the multi-attribute auction more easier to implement and operate; Besides, the method meets the incentive compatibility and participation constraint conditions under which the highest bidding supplier will win the auction.
\end{abstract}

\section{Introduction}

Auction mechanisms have been widely used in electricity procurement and other fields (Schottmüller, et al., 2016), and thanks to the rapid economic developments, China is becoming one of the largest procurement markets in the world. This drives research focus on the reverse auction, which mainly consists of government procurement. As the single-attribute price auction can't meet the requirements of bulk procurement on the attributes of quality, delivery time, aesthetic characteristics and service level and so on, thus resulting in the research requirements of multi-attribute auction at a broader scale (Bichler, 2000).

Multi-attribute auction has greater applicability than single-attribute auction, but the complexity of the mechanisms leads to relatively slow developments in the process of procurement. Like as in many procurement activities, if the single-attribute auction mechanism is used to determine the transaction only by price, non-price attributes such as quality can not be guaranteed to meet the requirements; and if the multi-attribute auction mechanism is used to bid for each attribute, the auction becomes complicated.

In view of the above problems, by using first-sealed auction mechanism method, takes into account of the advantages of single-attribute auction with multi-attribute auction, this article presents a new mechanism of multi-attribute reverse auction on margin bid. The mechanism is designed as: each supplier cannot bid more than its net profit (which is the supplier's private information).

\section{Literature Review}

Much of the research on multi-attribute auction theory is based on the work of Che (1991), such as the risk types of buyer and supplier, the collusion in auction and so on. In order to study multi-attribute auction, he built a two-dimensional attributes model of government bidding and procurement, which examines the basic research for multi-attribute auction. Based on aforementioned research, the optimal mechanism for maximizing the total social surplus is studied (Branco, 1997), assuming that the bidders' costs are correlated. Further studies showed (Rezende, et al., 2002) that auctioneers can devise a scoring function in the form of utility function that enhances the competition between bidders and thus brings greater revenue to the auctioneer.

In the real life, each supplier and buyer has different risk preference. So to address the different risk perceptions, Cobb-Douglas utility function is used to discuss the impact on the equilibrium bidding strategy and compared the expected utility of the buyer (Li, et al., 2012). Another solution to eliminate risk perception is Arrow-Pratt measure, which, is used to study the situation when both 
buyer and sellers are risk averse, can be used to discuss the profit distribution between the two parties under cooperative and non-cooperative conditions (Tian, et al., 2014).

Collusion is a common phenomenon in the auction (Fugger, et al., 2015), results from previous research show that when the bidder increases or the uncertainty variable declines, the probability of forming a collusive price will decrease. For considering third-party agencies (Zhu, et al., 2016), it is argued that in order to effectively prevent collusion, in addition to paying the auctioneer a fixed fee, buyer should pay an extra payment to the auctioneer.

With the rise of e-commerce in developing economies (Kauffman, et al., 2005), online fraudulent behavior is likely to appear in the internet auction. Empirical researches based on auction websites (Bichler, 2000; Chen, 2005), the results pointed towards the fact that multi-attribute auction can bring greater utility to buyer and sellers in comparison to single-attribute auction. Also by optimizing contract parameters ( $\mathrm{Li}$, et al., 2015), retailers can continuously reduce the cost of information, and retailers can overcome the problem of asymmetric information to maximize supply chain profits under specific conditions.

Designing a reasonable model to make it more realistic and effectively application to practice is the key to the auction theory (Karlsson, 2016). Later, David, et al. (2006) extended the multi-attribute auction to any number of attribute scenarios, and the article also made a corresponding study on the determination of the scoring function when the buyer profited the most. Based on the research by David, an improved multi-attribute auction model is proposed to make it more applicable and give a balanced bidding strategy for this model (Sun, et al., 2010). In the theory of single-attribute auction, there is a theorem that the buyer has the same expected profit by using four kinds of the auctions. Asker et al. (2004) showed that this expectation of equal returns also exists in the multi-attribute auction. Later Zeng et al. (2014) also used the improved model to prove the payoff equivalence theory. In order to know buyer's preference information, knowing of the buyer's preference is the key to winning the bid (Yang, et al., 2014).

\section{The model}

Assumption 1 Single buyer and $n$ number of suppliers, buyer and suppliers are risk-neutral.

Assumption 2 Quality $q$ and delivery time $l$ of supplier-supplied product are independent of each other, and the quality $q$ and delivery time $l$ are both determined by the technology type of $\theta$. Furthermore the supplier of technology type $\theta$ obeys $[\underline{\theta}, \bar{\theta}]$, The distribution function is $f(\theta)=$ $1 /(\bar{\theta}-\underline{\theta})$, and the density function is $F(\theta)=(\theta-\underline{\theta}) /(\bar{\theta}-\underline{\theta})$.

Assumption 3 Suppose that the net utility function of supplier $i$ is:

$$
v\left(\theta_{i}\right)=p\left(\theta_{i}\right)-\frac{1}{\theta_{i}}\left[k_{1} q^{t_{1}}\left(\theta_{i}\right)+k_{2}\left(L-l\left(\theta_{i}\right)\right)^{t_{2}}\right]=p_{i}-c\left(q_{i}, l_{i}, \theta_{i}\right)
$$

Where $k_{1} 、 k_{2}$ are greater than zero, the supplier is given the weight of attribute $q_{i}$ and attribute $l_{i}$. To satisfy $c_{q}>0, c_{q q}>0$ and $c_{l}<0, c_{l l}>0$, we have $t_{1} \geq 1, t_{2} \geq 1$. And $p_{i}$ is a short for $p\left(\theta_{i}\right)$, and the subsequent similar forms have the same meanings. When supplier $i$ bid on margin $V\left(\theta_{i}\right)$, which is not to be returned, the expected return is:

$$
\pi\left(\theta_{i}\right)=\left[p\left(\theta_{i}\right)-c\left(q\left(\theta_{i}\right), l\left(\theta_{i}\right), \theta_{i}\right)-V\left(\theta_{i}\right)\right] \operatorname{prob}\left[V\left(\theta_{-i}\right)<V\left(\theta_{i}\right)\right]
$$

When a bidding firm with a true technical type of $\theta_{i}$ reports that, it's technical type is $\mathrm{x}$ (that is, when the supplier negotiates the product quality), the expected return is:

$$
\pi\left(\mathrm{x}, \theta_{i}\right)=\left[p(x)-c\left(q(x), l(x), \theta_{i}\right)-V\left(\theta_{i}\right)\right] \operatorname{prob}\left[V\left(\theta_{-i}\right)<V\left(\theta_{i}\right)\right]
$$

The incentive compatible constraint is:

$$
\forall x, \theta_{i} \in[0,1], \pi\left(\theta_{i}, \theta_{i}\right) \geq \pi\left(x, \theta_{i}\right)
$$

$\Pi \pi\left(\theta_{i}, \theta_{i}\right)$ indicates that the bidding company, whose technical type is $\theta_{i}$, reports its own technical type as $\theta_{i}$. 
This also needs to meet the participation constraints:

$$
\pi\left(\theta_{i}\right)=\left[p\left(\theta_{i}\right)-c\left(q\left(\theta_{i}\right), l\left(\theta_{i}\right), \theta_{i}\right)-V\left(\theta_{i}\right)\right] \operatorname{prob}\left[V\left(\theta_{-i}\right)<V\left(\theta_{i}\right)\right] \geq 0
$$

Now suppose the utility function of buyer is:

$$
\begin{aligned}
U_{i}= & \omega_{1} q^{S_{1}}\left(\theta_{i}\right)+\omega_{2}\left(L-l\left(\theta_{i}\right)\right)^{S_{2}}-p\left(\theta_{i}\right)+V\left(\theta_{i}\right) \\
& =R\left(q_{i}, l_{i}\right)-p_{i}+V_{i}
\end{aligned}
$$

Where $\omega_{1} \& \omega_{2}$, both are greater than zero, giving the buyer the weight of attribute $q_{i}$ and attribute $l_{i} .0<S_{1} \leq 1,0<S_{2} \leq 1$ in order to meet $R_{q}>0, R_{q q}<0$ and $R_{l}<0, R_{l l}<0$.

\section{Equilibrium bidding strategy}

By using the first price-sealed auction method in this paper, we have the following theorem:

Theorem 1: Under the given assumption before, in the multi-attribute reverse auction on margin bid, the bidder's bid of $V\left(\theta_{i}\right)$ (bidding strategy) is:

$$
V_{i}=\frac{n-1}{n} v_{i}=\frac{n-1}{n}\left[p_{i}-c\left(q_{i}, l_{i}, \theta_{i}\right)\right]
$$

Proof: Knowing the probability of winning:

$$
\operatorname{prob}\left[\mathrm{V}\left(\theta_{-\mathrm{i}}\right)<\mathrm{V}\left(\theta_{\mathrm{i}}\right)\right]=\operatorname{prob}\left[\mathrm{V}\left(\mathrm{v}_{-\mathrm{i}}\right)<\mathrm{V}\left(\mathrm{v}_{\mathrm{i}}\right)\right]=\mathrm{F}^{\mathrm{n}-1}\left(\mathrm{~V}^{-1}\left(\mathrm{~V}\left(\mathrm{v}_{\mathrm{i}}\right)\right)\right)
$$

The expected return of the supplier can be expressed as:

$$
\pi\left(\theta_{\mathrm{i}}\right)=\left[\mathrm{v}\left(\theta_{\mathrm{i}}\right)-V\left(\theta_{i}\right)\right] \Phi^{n-1}\left(V_{i}\right)
$$

The optimal first-order condition for bidding to maximize $\pi\left(\theta_{i}\right)$ is:

$$
-\Phi\left(V_{i}\right)+\left[v_{i}-V_{i}\right](\mathrm{n}-1) \Phi^{\prime}\left(V_{i}\right)=0
$$

However, $F\left(V^{-1}\left(V\left(v_{i}\right)\right)\right)=\Phi\left(V_{i}\right)=F\left(v_{i}\right)=\frac{v_{i}-\underline{\theta}}{\bar{\theta}-\underline{\theta}}$, it can be seen from equation (1), which can be transformed into:

$$
-\Phi\left(V_{i}\right)+\left[\underline{\theta}+(\bar{\theta}-\underline{\theta}) \Phi\left(V_{i}\right)-V_{i}\right](\mathrm{n}-1) \Phi^{\prime}\left(V_{i}\right)=0
$$

By solving equation (2), we can have the results for margin, which is shown by equation below:

$$
V\left(\theta_{i}\right)=\frac{n-1}{n} v_{i}=\frac{n-1}{n}\left[p_{i}-c\left(q_{i}, l_{i}, \theta_{i}\right)\right]
$$

Theorem 2: While creating a new mechanism, which bid on margin, the optimal transaction attributes proposed by the buyer to the supplier is the same as the study of David (2005).

$$
\left\{\begin{array}{l}
p_{i}^{*}=c\left(q_{i}, l_{i}, \theta_{i}\right)-\int_{\underline{\theta}}^{\theta_{i}} c_{\theta}(q, l, \theta)\left[\frac{F(\theta)}{F\left(\theta_{i}\right)}\right]^{n-1} d \theta \\
q_{i}^{*}=\left(\frac{\omega_{1} \cdot S_{1} \cdot \theta_{i}}{k_{1} \cdot t_{1}}\right)^{\frac{1}{t_{1}-S_{1}}} \\
l_{i}^{*}=L-\left(\frac{\omega_{2} \cdot S_{2} \cdot \theta_{i}}{k_{2} \cdot t_{2}}\right)^{\frac{1}{t_{2}-S_{2}}}
\end{array}\right.
$$

Proof: The supplier will eventually accept the buyer's property requirements and provide the corresponding attributes of the product.

Using the same method as Che (1991) and David (2005), we can know that the final transaction price is:

$$
p\left(\theta_{i}\right)=c\left(q_{i}, l_{i}, \theta_{i}\right)-\int_{\underline{\theta}}^{\theta_{i}} c_{\theta}(q, l, \theta)\left[\frac{F(\theta)}{F\left(\theta_{i}\right)}\right]^{n-1} d \theta
$$

The total social income is: 


$$
\mathrm{E}=\omega_{1} q^{S_{1}}\left(\theta_{i}\right)+\omega_{2}\left(L-l\left(\theta_{i}\right)\right)^{S_{2}}-\frac{1}{\theta_{i}}\left[k_{1} q^{t_{1}}\left(\theta_{i}\right)+k_{2}\left(L-l\left(\theta_{i}\right)\right)^{t_{2}}\right]
$$

Then the quality of the transaction is:

$$
q_{i}^{*}=\operatorname{argmax}\left\{\omega_{1} q^{S_{1}}\left(\theta_{i}\right)+\omega_{2}\left(L-l\left(\theta_{i}\right)\right)^{S_{2}}-\frac{1}{\theta_{i}}\left[k_{1} q^{t_{1}}\left(\theta_{i}\right)+k_{2}\left(L-l\left(\theta_{i}\right)\right)^{t_{2}}\right]\right\}
$$

Delivery time is:

$$
l_{i}^{*}=\operatorname{argmax}\left\{\omega_{1} q^{S_{1}}\left(\theta_{i}\right)+\omega_{2}\left(L-l\left(\theta_{i}\right)\right)^{S_{2}}-\frac{1}{\theta_{i}}\left[k_{1} q^{t_{1}}\left(\theta_{i}\right)+k_{2}\left(L-l\left(\theta_{i}\right)\right)^{t_{2}}\right]\right\}
$$

By using partial derivative, and make equation (3) equal to zero, we can conclude:

$$
\begin{aligned}
& q_{i}=\left(\frac{\omega_{1} \cdot S_{1} \cdot \theta_{i}}{k_{1} \cdot t_{1}}\right)^{\frac{1}{t_{1}-S_{1}}} \\
& l_{i}=L-\left(\frac{\omega_{2} \cdot S_{2} \cdot \theta_{i}}{k_{2} \cdot t_{2}}\right)^{\frac{1}{t_{2}-S_{2}}}
\end{aligned}
$$

Theorem 3: In this paper, the model satisfies the incentive compatible constraint and the supplier will not hide his true information.

Proof: When the supplier's real technology type is $\theta_{i}$, and he hides the information and misrepresents that the type is $x$, the expected profit is:

$$
\pi\left(x, \theta_{i}\right)=\frac{1}{n}\left[p(x)-c\left(q(x), l(x), \theta_{i}\right)\right] F^{n-1}(x)
$$

And by using $p(x)=c(q(x), l(x), x)-\int_{\underline{\theta}}^{x} c_{\theta}(q(\theta), l(\theta), \theta)\left[\frac{F(\theta)}{F(x)}\right]^{n-1} d \theta$

We can know conclude $\pi\left(\theta_{i}, \theta_{i}\right)-\pi\left(x, \theta_{i}\right)$

$$
=\frac{1}{n} \int_{\theta_{i}}^{x}\left[c_{\theta}(q(\theta), l(\theta), \theta) F^{n-1}(\theta)-c_{\theta}(q(x), l(x), \theta) F^{n-1}(x)\right] d \theta
$$

As we know $q(\theta)$ is an increasing function of the type of technology $\theta$, and delivery time $l(\theta)$ is a decreasing function of the technology type $\theta$.

$$
\text { (i) when } x>\theta_{i}, \theta \in\left[\theta_{i}, x\right]
$$

By $q(x)>q(\theta), c_{\theta q}<0$ and $l(\theta)>l(x), c_{\theta l}>0$, we have:

$$
c_{\theta}(q(\theta), l(\theta), \theta)>c_{\theta}(q(x), l(x), \theta)
$$

And since the distribution function $F(\cdot)$ increases with respect to the type of technology $\theta_{i}$, $F^{n-1}(x)>F^{n-1}(\theta)$

Can know : $c_{\theta}(q(\theta), l(\theta), \theta) F^{n-1}(\theta)>c_{\theta}(q(x), l(x), \theta) F^{n-1}(\theta)>c_{\theta}(q(x), l(x), \theta) F^{n-1}(x)$

Which is : $\pi\left(\theta_{i}, \theta_{i}\right)-\pi\left(x, \theta_{i}\right)>0$

$$
\text { (ii) when } x<\theta_{i}, \theta \in\left[x, \theta_{i}\right]
$$

By $q(\theta)>q(x), c_{\theta q}<0$ and $l(x)>l(\theta), c_{\theta l}>0$, we have:

$$
c_{\theta}(q(\theta), l(\theta), \theta)<c_{\theta}(q(x), l(x), \theta)
$$

We can know:

$$
c_{\theta}(q(\theta), l(\theta), \theta) F^{n-1}(\theta)<c_{\theta}(q(x), l(x), \theta) F^{n-1}(\theta)<c_{\theta}(q(x), l(x), \theta) F^{n-1}(x)
$$

Which is:

$$
\pi\left(\theta_{i}, \theta_{i}\right)-\pi\left(x, \theta_{i}\right)>0
$$

The above proof shows that the supplier will not hide his real information. Hence, the mechanism meets the incentive compatible constraints. 


\section{Conclusion}

The main conclusions of this paper are: (1) the method introduced in this paper can make multi-attribute auction easier to operate and implement as well as reducing the risk of supplier's abandon bid risk. (2) It ensures that the supplier will satisfy the incentive compatible constraint and individual rational constraint. So, the supplier with the highest producer wins the auction. (3) Compared with the existing traditional multi-attribute auction, this method can bring more expected benefits to buyer.

\section{Acknowledgements}

This work was supported by the National Natural Science Foundation of China (No. 71372061).

\section{References}

[1] Asker J, Cantillon E. “Equilibrium in scoring auction”. FEEM working paper, 2004, (148:4).

[2] Bichler M. “An experimental analysis of multi-attribute auction”. Decision Support Systems, 2000, (29:3), pp. 249-268.

[3] Branco F. “The Design of Multidimensional Auction”. Rand Journal of Economics, 1997, (28:1), pp. 63-81.

[4] Che Y K. "Design Competition through Multidimensional Auction”. Rand Journal of Economics, 1991, (24:4), pp. 668-680.

[5] Chen-Ritzo C H, Harrison T P, Kwasnica A M, et al. "Better, faster, cheaper: An experimental analysis of a multi-attribute reverse auction mechanism with restricted information feedback". Management Science, 2005, (51:12), pp. 1753-1762.

[6] Esther David, Rina Azoulay-Schwartz, Sarit Kraus. "Bidding in sealed-bid and English multi-attribute auction”. Decision Support Systems, 2006, (42:2), pp. 527-556.

[7] Fugger N, Katok E, Wambach A. "Collusion in dynamic buyer-determined reverse auction". Management Science, 2015, (62:2), pp. 518-533.

[8] Huang He, Chen Jian. "Mechanism design on auctioning procurement contracts and bargaining". Journal of Management Sciences in China, 2010, (13:3), pp. 1-7.

[9] Karlsson N. "Control problems in online advertising and benefits of randomized bidding strategies”. European Journal of Control, 2016, (30:15), pp. 31-49.

[10] Kauffman R J, Wood C A. "The effects of shilling on final bid prices in online auction". Electronic commerce research and Applications, 2005, (4:1), pp. 21-34.

[11] Li Jun, Liu Shulin. "Multi-attribute procurement auction based on Cobb-Douglas utility function”. Journal of Management Sciences in China, 2012, (15:3), pp. 54-60.

[12] Li Z, Shao L, Sun D. "Designing Multi-Attribute Procurement Mechanisms for Assortment Planning”. Decision Sciences, 2015, (46:3), pp. 597-622.

[13] Rezende, Leonardo. "Biased Procurement”. Stanford University Working Paper. 2002.

[14] Schottmüller C, Boone J. "Procurement with specialized firms”. Rand Journal of Economics, 2016, (47:3), pp. 661-687.

[15] Sun Yahui, Feng Yuqiang. "Multi-attribute sealed-bid auction model and optimal bidding strategies”. Systems Engineering-Theory \& Practice, 2010, (30:7), pp. 1185-1189.

[16] Tian Jian, Chen Qu. "Research on Profits Allocation between Supplier and Buyer with Risk-aversion in Multi-Attribute Reverse Auction”. Chinese Journal of Management Science, 2014, (22:09), pp. 33-39. 
[17] Yang N, Liao X, Huang W W. "Decision support for preference elicitation in multi-attribute electronic procurement auction through an agent-based intermediary”. Decision Support Systems, 2014, 57, pp. 127-138.

[18] Zeng Xianke, Feng Yuqiang. "Bidding strategies and revenue analysis for reverse multi-attribute auction”. Journal of Management Sciences in China, 2015, (18:9), pp. 24-33.

[19] Zhu Ge, Andrew B. Whinston. "Mechanism design and Implementation of online multi-attribute procurement auction with the objective of maximizing social welfare”. Management Review, 2016, pp. 47-60. 